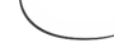

\title{
A forma auto-organizada da produção dos espaços públicos de vizinhança: o caso do bairro do Conjunto Ceará em Fortaleza (CE)
}

\author{
Rodrigo Holanda Barbosa ${ }^{1}$
}

Geovani Jacó de Freitas ${ }^{2}$

Universidade Estadual do Ceará

\begin{abstract}
Resumo: Esse artigo apresenta-se como aporte dos amadurecimentos de pesquisas científicas sobre a produção dos espaços públicos do Conjunto Ceará, na cidade de Fortaleza. Nos conta a história oficial do bairro, oriundo de um projeto urbanístico estatal e das lutas dos movimentos sociais pela preservação/reconhecimento desses espaços. Em seguida, traçando um contraponto, narra a história que opera no detalhe do cotidiano dos espaços públicos, apresentando a auto-organização como um processo pelo qual, a partir de ações desencadeadas por si mesmas, agentes, como os moradores do Conjunto Ceará, transformam os espaços públicos que fazem parte de suas vidas, superando dificuldades e atualizando potencialidades. A produção auto-organizada dos espaços públicos de vizinhança pelos próprios moradores aparece como parte vital de uma forma de habitar, inventiva, astuciosa e cotidiana, bem como, uma ação política de sujeitos comuns sob a banalidade do seu cotidiano, que esconde um potencial grandioso, porém fragmentado, de produção da realidade.
\end{abstract}

Palavras-chave: auto-organização; cotidiano; conflito; espaço público. 


\title{
The self-organized way of producing public neighborhood spaces: the case of Conjunto Ceará neighborhood in Fortaleza (CE)
}

\begin{abstract}
This article presents itself as a contribution to the maturation of ethnographic researches on the production of public spaces in Conjunto Ceará. It tells us the official history of the neighborhood, arising from a state urban project and the struggles of social movements for the preservation/recognition of these spaces. Then, drawing a counterpoint, he narrates the story that operates in the detail of the daily life of public spaces, presenting self-organization as a process by which, based on actions triggered by themselves, agents, such as the residents of Conjunto Ceará, transform the public spaces, overcoming difficulties and updating potential. The self-organized production of public neighborhood spaces by the residents themselves appears as a vital part of an inventive, astute, and daily way of living, as well as a political action by ordinary subjects under the banality of their daily lives, which hides a great potential, however fragmented, of producing reality.
\end{abstract}

Keywords: self-organization; daily; conflict; public place.

\section{La forma autoorganizada de producir espacios públicos barriales: el caso del barrio Conjunto Ceará en Fortaleza (CE)}

\begin{abstract}
Resumen: Este artículo se presenta como un aporte a la maduración de investigaciones etnográficas sobre la producción de espacios públicos en el Conjunto Ceará. Nos cuenta la historia oficial del barrio, surgida de un proyecto urbano estatal y de las luchas de los movimientos por la preservación/reconocimiento de estos espacios. Luego, trazando un contrapunto, presenta la autoorganización como un proceso por el cual, a partir de acciones desencadenadas por ellos mismos, agentes, como los vecinos del Conjunto Ceará, transforman los espacios públicos, superando dificultades y actualizando potencialidades. La producción autoorganizada de los espacios públicos del barrio por parte de los propios vecinos aparece como parte vital de una forma de vida inventiva, astuta y cotidiana, así como una acción política de los sujetos ordinarios bajo la banalidad de su cotidianidad, que esconde un gran potencial, por fragmentado que sea, de producir la realidad.
\end{abstract}

Palabras clave: autoorganización; diario; conflicto; lugar público. 
Está escrito, no grande livro da sabedoria popular. Que primeiro se deve viver, que é pra depois poetar. Que primeiro se deve viver, que é pra depois poetar.

Ednardo, em Está escrito. Cantor e compositor fortalezense.

$\mathrm{P}$ erde-se, na banalidade do cotidiano, uma história que é eclipsada, tanto frente à história oficial construída pela estrutura hegemônica, quanto pelas lutas maiores em reivindicação de melhorias via Estado. As histórias mais ordinárias do cotidiano e da convivialidade, incluindo aquelas relacionadas com a produção dos espaços públicos de vizinhança por homens e mulheres comuns, sistematicamente, são consideradas pelo senso comum (inclusive "douto") como um conjunto de eventos sem importância.

Durante nossa inserção nas pesquisas de iniciação científica em 2015 e em sua prolongação em 20163, de título: "Segurança, insegurança e cidadania: lutas por reconhecimento e por preservação de espaços públicos de lazer - estudos sobre o Conjunto Ceará na cidade de Fortaleza"4, tivemos a curiosidade de voltar nossa atenção à banalidade da vida dos sujeitos comuns e à política feita no cotidiano ordinário (CERTEAU, 1998)

Assim, em paralelo, desempenhamos com tal interesse no cotidiano, uma outra pesquisa com esse foco e profundidade para o trabalho monográfico de conclusão de curso de Ciências Sociais na Universidade Estadual do Ceará em $2017^{5}$. Por conseguinte, este artigo é o resultado inédito da maturação desse amplo período de pesquisa, que acumulado, soma o total de 4 anos.

Nossa pesquisa, inicialmente, perguntava-se como acontece a produção dos espaços públicos de vizinhança no Conjunto Ceará? E a resposta mais imediata que pensávamos era a de que nos referimos à ordem estatal como a grande responsável, tanto pela produção desses espaços, como pela manutenção e preservação deles e de seus usos.

Tendo em vista que, na tradição de pesquisa que se reuniu em volta da revista Année Sociologique, na qual compreende em destaque o antropólogo Marcel Mauss e é representada pelo sociólogo Émille Durkheim, o Estado aparece como portador de todo feito nos espaços públicos. Concepção estampada na denominação do Estado por Durkheim (2015) como "cérebro social".

Contudo, em crítica ao discurso do "monopólio do fazer" do Estado, lembrávamos que o habitar relaciona-se a uma produção do espaço que transcende a produção do território. De acordo com Breviglieri (2006), o habitar pressupõe familiaridade, participação, engajamento e a maneira como os indivíduos colocam-se no mundo em que vivem. Logo, a produção do espaço que se relaciona ao ato de habitar é em sua diferenciação, uma produção de lugares em que vários

3 Agradecemos o ao Conselho Nacional de Desenvolvimento Científico e Tecnológico (CNPq) e a Fundação Cearense de Apoio ao Desenvolvimento Científico e Tecnológico (FUNCAP) pelo fomento às pesquisas.

4 Cf. Relatórios técnicos de pesquisa 2015-2016 e 2016-2017.

5 Intitulado "Violências estatais e resistências: auto-organização dos espaços públicos no Conjunto Ceará". 
agentes múltiplos impregnam sentidos e valores aos espaços.

O espaço é construído como "lugar" por seus habitantes, quando de forma porosa absorve as experiências, lembranças e significados que as práticas cotidianas dos agentes imprimem nele. Marc Augé (2012: 53) ensina que "o lugar é necessariamente histórico a partir do momento em que, conjugando identidade e relação, ele se define por uma estabilidade mínima”. Deste modo, num lugar podem coexistir elementos distintos e singulares, porém "sobre os quais não se proíbe pensar nem as relações, nem a identidade partilhada que lhes confere a ocupação do lugar comum” (idem).

Estas questões primordiais nos remeteram ao conflito como categoria de análise dos lugares. Pois, como assevera Simmel (1983), o conflito é uma categoria intrínseca da vida e nosso mundo é feito inerentemente de luta. Divergente de Durkheim nesse ponto, não há na teoria simmeliana, unidade mediada por uma harmonia imóvel, mas sim, é na própria divergência que os indivíduos conservam-se mudando.

Assim, entendemos que a convivência dos lugares no mundo da vida é conflituosa e gera lutas de produção do espaço público que vão desde as maiores, envolvendo instituições e sua massificação, até aquelas imperceptíveis aos olhos naturalizados do cotidiano, mas que são igualmente importantes para compreendermos cientificamente a dinâmica social.

Nesse sentido, para averiguarmos nossa hipótese trabalhamos a partir de incursões de campo durante quatro anos, acompanhando e participando de experiências, registrando-as, nesse percurso de observação e confronto de olhares, com o uso permanente do diário de campo como instrumento auxiliar de grande valia na pesquisa.

Nossa configuração metodológica de pesquisa envolveu a observação participante, a técnica de gravação de entrevistas, participação de rodas de conversa sobre a memória no bairro, diálogos informais com transeuntes, além de ampla pesquisa bibliográfica de documentos públicos, documentação histórica, leis promulgadas, produção acadêmica, entre outras fontes consideradas ao longo do percurso.

Nos contatos que tivemos com os moradores do Conjunto Ceará procuramos compreender sobre a produção dos espaços públicos das suas vizinhanças. Buscamos ouvir uma multiplicidade de sujeitos, desde lideranças que estavam atuando nas lutas interinstitucionais do bairro, como os cidadãos comuns, aqui compreendidos como agentes que atuam no cotidiano ordinário. Desconfiávamos que essa dinâmica de produção dos espaços públicos de vizinhança não seria exclusiva de uma minoria politizada e que cada ação continha um poder de transformação.

Inclusive, tivemos ao nosso favor, o fato de sermos pesquisadores e sujeitos da pesquisa ao mesmo tempo, pois também somos moradores do Conjunto Ceará. Logo, em nosso caso, uma separação forçada entre sujeito e objeto, como requer uma suposta neutralidade positivista, seria como uma vivissecção de sapos, em que o estudo é feito, mas a vida se esvai na construção do objeto.

Acreditamos que nossa interligação possibilita a oscilação do olhar de dentro e de fora, que em vez de pretender a dominar o conhecimento, no status de sujeito conhecedor, "experimenta a si mesmo expondo-se ao risco de perder sua autocerteza e o chão firme de seu saber" (FLICKINGER e NEUSER, 1994: 40).

Nesse sentido, a forma escolhida de linguagem para esse artigo diz muito sobre uma representação "ombro à ombro", tecida como uma narrativa histórica. Por isso, pode ser que as falas dos outros moradores pareçam ao leitor figurarem 
como exemplos confirmatórios, sendo sinal de que conseguimos chamar todos os sujeitos a falar lado a lado, inclusive os pesquisadores, numa só narrativa coletiva que se confirma.

No século XXI, era da rápida difusão propiciada pelo estreitamento comunicativo da internet e das tecnologias digitais de informação, a perspectiva é a de fim por completo do pesquisador como ser "alienígena" na realidade. Aquela imagem que revolucionou a antropologia até então "de gabinete", levando-a ao campo, de um antropólogo, homem branco e europeu no centro de uma fotografia e ao redor de nativos, parece-nos que dá lugar hoje a uma nova aproximação sujeito-objeto, no qual o próprio nativo que apreende evidências através de sua câmera de celular, por exemplo.

Neste artigo, primeiramente, vamos apresentar a reconstituição da história oficial dos espaços públicos do Conjunto Ceará oriundos do projeto urbanístico estatal que lhe deu origem e das lutas de movimentos sociais do bairro pela preservação/reconhecimento desses espaços, como a luta por saúde no Hospital Municipal Nossa Senhora da Conceição, a luta por educação nas Escolas Secundaristas "UV2-UV8" e a luta por lazer no Polo Luiz Gonzaga. Em seguida, traçando um contraponto, narramos a história que opera no detalhe do cotidiano dos espaços públicos de vizinhança, como o campo de areia batida "Now Roots", o "Jardim da 335" de plantas medicinais e ornamentais, e, a "Pista Velha de Skate" e seus saraus no coração do bairro. Desta forma, apresentamos a auto-organização como um processo pelo qual, a partir de ações desencadeadas por si mesmas, agentes, como os moradores do Conjunto Ceará na cidade de Fortaleza, transformam os espaços públicos de vizinhança que fazem parte de suas vidas, superando dificuldades e atualizando potencialidades.

\section{A história oficial do Conjunto Ceará e de seus espaços públicos de vizinhança}

Na década de 1960, houve criações como a do Banco Nacional de Habitação (BNH) e as Companhias Estaduais de Habitação (COHAB). Nesse período, exatamente no ano de 1967, teve início a construção do bairro do Conjunto Ceará pela COHAB do Ceará, criado pelo governo de Plácido Aderaldo Castelo. Esse pioneiro conjunto habitacional em termos urbanísticos, reconhecidamente, por ser uma "cidade" dentro da cidade de Fortaleza, teve sua inauguração completa somente em 1978 e sua lei de decreto somente em 1989.

O Conjunto Ceará foi constituído em quatro etapas, frutos do gigantesco "Projeto Ceará" que deu origem ao nome do bairro. A totalidade do terreno da empreitada abrangeu uma área de 389 hectares de terra e oferecia 4 tipos de casas, caracterizadas de A-D, variando de tamanho entre 23-57 m² (VIANA, 1996).

Construído na periferia da Cidade em função do baixo custo dos terrenos, a região era desprovida de qualquer estrutura urbana. Situada numa baixada, a área consistia de várias várzeas lotadas de carnaúbas, por situar-se na região que compõe a bacia hidrográfica do Rio Maranguapinho. Logo, o território era propenso a alagamentos em períodos de inverno, situação mitigada pela construção de canais que cortam o bairro e que, atualmente, poluídos escoam o esgoto de toda a zona urbana ao redor. Por este motivo, segundo os relatos propiciados pela escuta dos moradores, as terras onde ficam a primeira e a terceira etapas eram 
chamadas de "estiva"6 e mais abaixo, na segunda e quarta etapas, as terras eram conhecidas como "Veneza".

Território limítrofe de Fortaleza, a região do bairro separa por uma ferrovia, o município de Caucaia, pertencente à Região Metropolitana de Fortaleza. Descobrimos em uma roda de conversa sobre a memória do bairro, organizada pelo "Makulelê"7, ao ouvir nos relatos dos moradores mais antigos, que além dos funcionários públicos que imaginávamos serem os primeiros moradores do Conjunto Ceará, os retirantes da seca chegavam do interior pelos trilhos do trem e se estabeleciam no bairro, sobretudo, nas casas de parentes e conhecidos.

O bairro foi inspirado no conceito moderno de Unidade de Vizinhança (UV), do arquiteto americano Clarence Arthur Perry (1929), no qual as avenidas são denominadas por letras e cercam o bairro pelas bordas, deixando-o repleto de ruas menores denominadas por números, constituindo, assim, um sistema alfanumérico próprio de localização. É comum, ainda hoje, que alguns visitantes se percam no bairro, mas quem cresce e habita no Conjunto Ceará aprende cedo no cotidiano essa orientação alfanumérica. Os moradores são hábeis em explicar que o número das ruas corresponde ao número da unidade de vizinhança e lembram em memória onde se localiza cada "UV" no território ${ }^{8}$.

A estratégia da "UV", com suas avenidas nas bordas, consiste em tornar o interior das zonas de ruas menores mais seguro, diminuindo o tráfego de veículos no interior do bairro e propiciando mais segurança para a mobilidade de seus moradores, ao mesmo tempo em que os equipamentos públicos disponíveis incentivassem práticas comunitárias.

Por isso, o projeto continha a construção de uma escola, um centro comercial de abastecimento, um núcleo comunitário (popularmente conhecido como "centrinho") e uma praça pública com jardins e quadras de esportes para cada unidade, que ao final da construção de 4 etapas, totalizaram 11 Unidades de Vizinhança (UV).

O Conjunto Ceará, bairro compreendido na Regional V de Fortaleza e que no último censo demográfico possuía 42.894 habitantes (IBGE, 2010), conta hoje com um posto policial, um posto de saúde, um hospital e maternidade, um liceu e uma vila olímpica, e, ainda, um Centro Social Urbano (CSU).

Com essa herança material do projeto urbanístico que deu origem ao bairro, o Conjunto Ceará costuma gozar de um reconhecimento social perante a Cidade, adquirindo um status de "centro da periferia". Tendo, de acordo com as memórias de nossos entrevistados, por esse motivo, ganhado um terminal urbano de ônibus na década de 1990. Inclusive, devemos destacar que a rica quantidade de espaços e equipamentos públicos na herança urbanística do Conjunto Ceará ampliou nossas possibilidades de observação científica das suas produções cotidianas.

Seus moradores, participam desse reconhecimento, quando relatam diferenças do bairro em relação a outros circunvizinhos e recordam em suas narrativas, as lutas de enfrentamento aos governos federal, estadual e municipal para cobrar ações e resistir a intervenções que não atendiam aos interesses da comunidade, procurando garantir a manutenção desse status que lhes confere distinção simbólica na periferia da Cidade.

${ }^{6}$ Substantivo feminino: Marinha, o fundo interno de um navio. Dicionário Online Dicio. Disponível em: https://www.dicio.com.br/estiva/ Acesso em: 26. ago. 2020.

7 Um bar histórico do bairro, situado no Polo de Lazer Luiz Gonzaga e de uma arquitetura icônica feita com a bricolagem de materiais descartados do artista local Pedro Araújo.

${ }^{8}$ Por exemplo: Unidade de Vizinhança 3 = Ruas que começam em 300 e não chegam a 400. 
Uma dessas lutas históricas foi a luta contra a passagem de linhões de altatensão elétrica da Companhia Hidroelétrica do São Francisco (CHESF), que deveria cortar o bairro caso não fosse a mobilização da comunidade, temendo seu perigo voltaico. Inclusive, nas memórias dos moradores mais antigos é sempre presente essa intensa capacidade, segundo eles próprios, de "fazerem-se ouvir" pelos poderes públicos. O morador Márcio resume bem o sentimento de luta que marca a sociabilidade do bairro:

\begin{abstract}
A gente tem que ser bem atendido nesses hospitais. Olha, não é de graça, esses hospitais saem do nosso bolso. É imposto pago por nós e como morador nós temos que cobrar. O morador do Conjunto Ceará tem que se unir e cobrar aquilo que é de direito. Eles não estão fazendo um favor a gente, eles tão lá porque nós votamos, eles estão para defender nossos interesses como cidadãos. (Morador Márcio Alexandre)
\end{abstract}

Entretanto, apesar do orgulho na identidade de morador, o Conjunto Ceará está envolvido em problemas comuns a qualquer comunidade periférica, tais como, amontoados de lixo residencial e entulhos, canais de esgoto a céu aberto, quedas de energia, falta de água, precariedade da estrutura e ensino das escolas, precariedade da estrutura e serviço de saúde, dentre outros, o que põe em xeque a validade material do status de "centro da periferia".

Assim, essa história oficial de construção do bairro e de seus espaços públicos por parte do poder público, desde o início é acompanhada de lutas reivindicatórias dessa construção promovida pelo Estado, ou seja, lutas por reconhecimento e preservação dos espaços públicos existentes desde os primórdios, bem como, também, acompanhada das transformações criativas que os próprios moradores fazem mediante as dinâmicas de habitar o bairro em seu cotidiano.

Portanto, conhecendo as características do território, dos sujeitos históricos que o habitaram e o conjunto das contradições existentes, percebidas e vividas individual e coletivamente no Conjunto Ceará revelamos os móveis de lutas históricas, em que movimentos e indivíduos do bairro produzem os espaços públicos pelo continuum conflituoso do cotidiano. Muitas das lutas coletivas e/ou ações individuais localizadas são movidas pela identificação do aumento das precariedades do bairro, ao mesmo tempo em que pelo esforço dos moradores de não permitirem que o bairro perca seu status de "centro da periferia".

Como assevera Michel Agier (2015: 485), a compreensão antropológica das cidades tem muito a ganhar não só ao ficar atenta ao que se perde nos espaços da "não cidade", como nos territórios periféricos, mas também, "ao que nasce ali mesmo, como expressão de uma dialética mais geral do vazio e do pleno, do fraco e do forte".

\title{
A produção dos espaços públicos pelos movimentos organizados de moradores do Conjunto Ceará: "Hospital da quarta", "CCPA" e "UV2-UV8"
}

Durante nossa pesquisa participamos das lutas dos movimentos sociais do Conjunto Ceará por meio do Fórum Comunitário de Lutas Unificadas que reunia diversas lideranças comunitárias.

A primeira luta que participamos e acompanhamos, refere-se a um lugar que as pessoas no bairro denominam como "hospital da quarta etapa". O Hospital Municipal e Maternidade Nossa Senhora da Conceição, situado na Rua 1018, $4^{\mathrm{a}}$ etapa do Conjunto Ceará. Sobre a história desse local, conforme resgatamos das memórias dos moradores, o prédio no qual se encontra o hospital era um dos "centrinhos" disponíveis do Projeto Ceará, o da Unidade de Vizinhança 10. Esse 
hospital, devido à precariedade dos serviços públicos de saúde da região periférica, conforme valorações e significações das pessoas, tornou-se vital não somente para o Conjunto Ceará, mas também para todos os bairros circunvizinhos que não possuem hospital e maternidade, como os bairros do Genibaú, Bom Jardim, Granja Portugal, Granja Lisboa e, até mesmo o bairro da Jurema, situado no município vizinho de Caucaia.

Apesar disso, a condição atestada pelos cidadãos que dependem do hospital era de péssima estrutura e atendimento. Em depoimento, um morador chegou a dar um sentido fúnebre ao local, designando a unidade de saúde como "matadouro".

Entretanto, após uma pane no sistema elétrico no prédio, a unidade hospitalar foi fechada no dia 22 de agosto de 2015, definitivamente, pela Prefeitura Municipal de Fortaleza, em prol da construção da Unidade de Pronto Atendimento no bairro. Isso não foi de agrado das lideranças e moradores do Conjunto Ceará porque recordavam a importância histórica do equipamento, apesar da sua situação precária. Logo, na manhã do dia 25 do mesmo mês, servidores e movimentos políticos fizeram um ato em frente ao local, desencadeando uma série de negociações entre as lideranças e a Prefeitura.

Tais mobilizações culminaram na realização de uma audiência pública que foi muito bem-vista pelos moradores. Realizada em conjunto com a Câmara Municipal de Fortaleza e a Assembleia Legislativa do Ceará, evento aberto ao público e ao ar livre, no meio do Polo de Lazer do Conjunto Ceará9, no dia 30 de Setembro de 2015. Resultando dessas mobilizações junto aos gestores públicos, a reversão da decisão de fechamento do hospital e a melhoria de seu funcionamento.

Outro exemplo que também retrata as resistências na luta por reconhecimento e reivindicação da produção/intervenção do Estado nos espaços públicos, estendeu-se desde o começo do ano de 2016 e ocorreu pela decisão da extinta COHAB (por meio da Prefeitura de Fortaleza) de leiloar vários prédios públicos e históricos que formam, junto a outros equipamentos, o Polo de Lazer Luiz Gonzaga. O lugar compreende o "coração" do bairro e é tradicionalmente ponto de encontro, sociabilidade e lazer da população.

Em um desses prédios postos a leilão, funcionava, na década de 1970, a Companhia Brasileira de Alimentos (COBAL-CE), importante serviço em uma época em que era bastante precário o abastecimento alimentar de conjuntos habitacionais periféricos. Entretanto, o local foi transformado numa mistura de shopping e centro cultural, denominado de Centro Cultural Patativa do Assaré (CCPA). Sob ameaça de leiloamento, em 2017, o equipamento foi ocupado pelos movimento de moradores, lojistas e grupos culturais, construindo juntos uma agenda de atividades político-culturais, pois esses agentes temiam a perca de um espaço de trabalho, cultura e lazer tão importante para o bairro.

Foi assim que, diante da pressão comunitária, em junho de 2017, o Governo do Estado do Ceará decide pelo não leiloamento, pelo repasse do prédio do CCPA para a Secretaria de Cultura (SECULT) e a gestão do centro cultural aos ocupantes, reconhecendo e preservando o espaço como valoroso para a comunidade. Uma vitória para os ocupantes, pois o prédio representa uma estrutura de memórias de vida que não podem se deixar sucumbir, seja a valoração de erguer seu negócio para os lojistas, seja as lembranças de resistências dos movimentos naquele espaço, ou a memória de curtir as festas de juventude para os moradores mais velhos.

9 Área central do bairro que aglomera diversos equipamentos públicos, a Igreja Católica Matriz Nossa Senhora da Conceição, estabelecimentos comerciais e de prestação de serviços para todo tipo de lazer. 
Por conseguinte, além do Fórum, acompanhamos e apoiamos a luta do movimento de estudantes secundaristas das escolas públicas do Conjunto Ceará. Inicialmente, a primeira mobilização ocorreu logo no final do ano de 2015, quando os estudantes secundaristas da Escola José Maria Campos de Oliveira, conhecida pelo número de sua unidade de vizinhança "UV8", receberam a notícia que a instituição deveria "fechar as portas" em 2016. Segundo a Secretaria da Educação do Ceará (SEDUC), por motivos de "otimização administrativa".

Contudo, no dia 26 de novembro de 2015, estudantes fardados e professores saem em caminhada com cartazes e faixas, fazendo um ato político contra o fechamento da escola em meio às ruas do Conjunto Ceará e conseguindo, devido a essa importante pressão coletiva, que a escola continuasse aberta.

No entanto, o ano de 2016 não trouxe paz para a escola e a luta pela educação não parou. Segundo nossos registros de campo, uma outra escola, de nome Dr. Gentil Barreira, também conhecida pelos moradores por meio do número de sua unidade "UV2", teve seu prédio demolido para reforma que se arrastava sem previsão de término. Em decorrência disso, toda a sua equipe (estudantes, professores e gestão) foi colocada nas dependências do "UV8", de forma que no turno da manhã funcionava uma escola e no turno da tarde a outra. De acordo com os estudantes, essa nova dinâmica resultou na piora das condições de ensino e aprendizagem, já precárias naquele momento. Para eles, a escola era uma "segunda casa" e a precariedade da estrutura de ensino cultivava um sentimento de indignação em praticamente todos.

Assim, nesse ano de 2016, em Fortaleza, houve uma mobilização histórica da categoria de professores da educação básica pública, culminando numa greve que fez transbordar uma onda de ocupações secundaristas, inspiradas nas ocupações das escolas de São Paulo e nas escolas do Chile, em 2006, em defesa da educação e em apoio às reivindicações dos professores.

Os secundaristas da "UV2" e da "UV8" se unem e tomam a iniciativa de ocupação do prédio em que funcionavam suas escolas, durante 5 meses. Vários outros estudantes, ligados a movimentos secundaristas de outras escolas da Cidade, também aderiram à mesma tática política de ocupação. No Conjunto Ceará, juntaram-se ao Movimento o Colégio Liceu do Conjunto Ceará e a Escola Dr. Ubirajara Índio do Ceará (conhecida como “UV7”). E avaliamos que a permissão dos pais e a abertura das escolas para a comunidade foram fatores de apoio decisivo para a massificação do Movimento.

Nas ocupações, participamos de cine-debates, muralismos, oficinas, confraternizações, mutirões de limpeza e outras atividades sociopedagógicas promovidas por estudantes em parceria com ativistas e movimentos sociais de Fortaleza. Os próprios secundaristas, demonstrando maturidade, dividiam-se para cuidar da escola e gerenciar o calendário de atividades. Nesse período conhecemos a fundo as histórias de jovens muito inteligentes do ensino público, alguns com trajetórias realmente muito difíceis e que nos faziam perguntar como diante de tantos problemas em seu jovial tempo de vida pessoal, aqueles adolescentes continuavam a importar-se tanto com os problemas da escola. Como Claser, menino pobre, negro e homossexual, que estava sempre à frente das atividades e pelo seu afinco sempre demonstrava a importância da Escola na sua vida.

A resistência que acompanhamos por completo foi a ocupação "UV2-UV8", finalizada por meio de uma desocupação truculenta. Nesse episódio, com a decisão dos professores pelo fim da greve, os alunos da ocupação que não tinham negociado ainda suas pautas com a SEDUC decidiram barrar a entrada dos outros alunos, fazendo uma barricada, na segunda-feira que deveriam voltar às aulas. A 
vizinhança revoltada por entender que eram os ocupantes que impediam a educação dos seus filhos, imperou em fazê-los desocuparem. Nós, mesmo como pesquisadores, fomos afetados pela fúria violenta, ainda logo cedo daquela manhã. Felizmente, os ânimos baixaram e a negociação foi feita até o fim da tarde, referendada após assembleia estudantil, desocupando a escola e atendendo parte de suas demandas.

\section{A produção auto-organizada dos espaços públicos de vizinhança no Conjunto Ceará: "Campinho Now Roots", "Jardim da 335" e "Pista Velha de Skate"}

Em nossa pesquisa acompanhamos e participamos de produções de lugares que foram criados pelos próprios moradores do Conjunto Ceará durante seu cotidiano ordinário. Empreendimentos frutos da política dos cidadãos comuns, levando em conta o interesse comunitário, muitas das vezes, contando apenas com a força e a disposição de vizinhos, amigos ou familiares.

Um desses produtos autóctones fica localizado próximo à Rua 303, do lado da Escola Edilson Brasil Soares, conhecida popularmente como "UV3". O espaço é um campo de areia de pequeno porte, denominado pelos seus agentes de "Campinho Now Roots". Segundo as memórias das pessoas sobre o local, anteriormente à criação do campo, havia uma quadra de concreto do lado de fora do Colégio que a comunidade usava, ainda resquício do projeto urbanístico planejador do bairro. O que nos contam é que o espaço tinha sido "jogado ao léu” e que em um dia, em época eleitoral, a mando de um vereador e sob suas promessas de reconstruí-la, a quadra que ainda era usada pelas crianças, apesar das suas condições, foi destruída. A promessa, para surpresa dos moradores, não foi cumprida e, durante meses, o local ficou deserto, abandonado.

Para a reconstituição da história do local, resgatamos ainda que havia outra quadra do lado de dentro da escola, própria para os estudantes da "UV3", feita de cimento e com cobertura que, contudo, devido à precariedade da estrutura da escola, o uso de materiais de péssima qualidade e em decorrência de fortes chuvas, teve a cobertura desabada, sem que tenha havido feridos na ocasião. Os destroços ficaram espalhados pelo chão e alguns materiais foram saqueados. Sem nenhuma perspectiva de reconstrução das duas quadras, os moradores da Unidade de Vizinhança 3 ficaram compelidos pela violência traduzida pela completa falta de opções de lazer na sua área de habitação. Ante essa situação, os moradores do entorno resolveram fazer eles mesmos um "campinho" com os alambrados da antiga quadra de dentro da escola e no espaço da antiga quadra do lado de fora. Em uma demonstração de produção do espaço público de forma auto-organizada, os moradores construíram um campo de areia batida, pintaram os muros arredores, plantaram mudas e circunscreveram o campo com pneus velhos.

Durante uma das partidas, quando perguntados quem cuidava do espaço, um dos jogadores que no momento assistia à partida de futebol respondeu-nos: "é nós mesmo", um outro ainda completou: "se não fosse a gente, isso aqui já tinha acabado". Logo, ficou muito patente em todos que ali estavam, que a força, a confiança e o compromisso daqueles moradores uns com os outros tinham ocasionado pela apropriação, uma transformação de um espaço até então abandonado em lugar de circulação do fluxo de vida do bairro.

A moradora Graça, que mora próximo ao campo, nos contou sua versão da história do local com muito orgulho, porque para ela, "os jovens precisam praticar 
esportes para se manter longe da vida do crime" e o campo teria o sentido de proporcionar isso as pessoas da vizinhança:

\begin{abstract}
Juntou o pessoal lá na quadra que tinha caído, falaram com o diretor (da escola), se podia usar as grades que estavam lá, aí o diretor cedeu, com os restos, pintaram e plantaram algumas plantas. [...] O pessoal joga bola aí quase todo dia. (Moradora Graça Almeida)
\end{abstract}

O campo fica ao lado de um dos centrinhos do projeto urbanístico que deu origem ao bairro, no qual agora funciona uma igreja evangélica. No muro desse centrinho que recebeu a pintura dos moradores, podem ser observados os seguintes dizeres: "Cuidamos e limpamos, a prefeitura é nóis!" Essas frases dos moradores, relembram-nos que as lutas políticas também são lutas morais (HONNETH, 2009) e expõem a dimensão simbólica desses agenciamentos. Portanto, notamos que a percepção dos moradores acerca da ausência do Estado naquele espaço faz com que haja uma perda na legitimidade dos poderes públicos e, consequentemente, uma diminuição na sua dominação simbólica.

Um fato curioso que acompanhamos durante a pesquisa etnográfica foi ter identificado que um dos usos do "Campinho Now Roots", acabou sendo, depois de um certo tempo, a prática de aulas de educação física dos próprios estudantes da UV3, certamente na falta da quadra nas dependências do Colégio. Observar os adolescentes fardados no exercício de atividades físicas coordenadas pelo professor, permitiu-nos compreender como a produção auto-organizada da moradores está em auxílio mesmo da dinâmica da escola que se encontra em seu espaço de vizinhança.

Outra produção auto-organizada é um jardim de plantas medicinais e ornamentais que fica localizado na Rua 335. O espaço fica situado em um terreno público baldio, como é comum nas periferias de Fortaleza. O local, pelo que escutamos de nossos interlocutores, constantemente é alvo de despejo indevido de lixo residencial, resíduos de construção de edifícios, móveis descartados etc. Já que, espaços residuais como esse, os quais não tiveram uma função programada na sua produção oficial do Estado, na produção cotidiana do habitar são incorporados pelos moradores que estabelecem práticas e usos, atribuindo-lhes significados.

Portanto, foi para ajudar na solução do problema de despejo indevido de lixo que o "Jardim da 335 " surgiu. Uma parte do terreno baldio foi delimitada com uma pequena cerca de madeira encravada ao chão e foi dado uma ocupação do solo pela plantação de mudas. Segundo Evelize, uma de nossas interlocutoras na pesquisa, moradora de frente ao jardim, cerca de 5 pessoas se revezam para cuidar do ambiente, cada um com seu dia e horário pra regar as plantas.

No jardim, existem papoulas, ipês e mais uma variedade de plantas, entre medicinais e ornamentais, adquiridas em um viveiro da cidade de Sobral, ou compradas em Fortaleza com o dinheiro arrecadado entre os próprios moradores.

Em uma das visitas ao local, recebemos relatos de que há alguns vizinhos do jardim que não compartilham o mesmo sentido da resistência, tendo como prática comum, a queima do lixo e da vegetação no terreno baldio, o que algumas vezes teria feito chegar o fogo até o recinto, infelizmente, queimando algumas plantas.

Nossa interlocutora Evelize depõe sobre as dificuldades da autoprodução desse lugar, da seguinte forma:

Porque antes, quando não tinha a cerca, o pessoal ainda jogava lixo aqui dentro! Agora, com a cerca que melhorou, mais ainda jogam e a gente tira. [...] apesar disso, se todo mundo cuidar um pouquinho aí dá certo. (Moradora Evelize Texeira) 
Nas narrativas dos moradores da Rua 335, a falta de consciência do restante da população é a maior dificuldade. Por isso, dentro do jardim existem placas que, além de decorativas, cumprem um papel sinalizador com dizeres do tipo: "Mantenha o jardim limpo e bem cuidado!" Elas expressam as significações e valorações dos moradores para o lugar, que além de ressoarem em como o jardim embeleza o espaço público de vizinhança, também ecoam a importância de um espaço limpo para a prevenção de doenças na comunidade.

Outro exemplo, popularmente chamada de "Pista Velha de Skate", situada no Polo de Lazer Luiz Gonzaga, o espaço é, na verdade, um tipo de pequeno anfiteatro, com alguns degraus ao seu redor, resquício dos anos 1990, que, historicamente, foi ocupado pelas tribos do skate, patins e outros esportes radicais, assim como também pela juventude do Conjunto Ceará em suas múltiplas pulsões de existência.

São os próprios usuários da pista que confeccionam os obstáculos necessários para a prática dos esportes, a exemplo de rampas feitas de pedaços de madeira, corrimões de ferro e outros tipos de materiais encontrados no lixo. Assim, eles próprios dão novas significações e contra-usos ao local, na medida que se adequam, adequam os espaços produzindo-os.

Produto de uma juventude periférica, silenciada e marginalizada, o espaço da pista sofre uma profunda deslegitimação, reforçada pelo abandono dos poderes públicos. Nas percepções de alguns moradores, costumamos ouvir que lá é um espaço de "vagabundos e drogados", porque o local é considerado ponto de uso e tráfico de drogas, mesmo localizado ao lado do $12^{\circ}$ Distrito Policial.

Na mesma medida, entretanto, o espaço é reconhecido no bairro como ponto de manifestações culturais e políticas desde muitas gerações. Os habitantes do lugar dão uma multiplicidade de sentidos que convivem juntos e o espaço aparece para eles como parte vital de suas vidas sociais, seja acerca da questão de socializar e reunir amizades, festejar, passear, comer e beber, praticar esportes radicais ou fazer caminhadas.

Na "Pista Velha de Skate", observamos e participamos de exposições de livros, oficinas de serigrafias e, sobretudo, apresentações dos próprios jovens moradores do bairro, a exemplo de música experimental, poesia, rock, rap e reggae. Todas essas variadas programações são parte de uma espécie de cultura alternativa que retrata o cotidiano das juventudes nas periferias.

Os "saraus" que acontecem, funcionam como um incremento da produção autóctone desse espaço público, na medida em que os usuários de skate continuam a usar a quadra ao som das músicas, assim como o fluxo do transitar de pessoas não é interrompido pelas apresentações. Todos esses elementos fazem parte da resistência complexa promovida pelos jovens, na produção e manutenção da Pista Velha de Skate, mesmo que originalmente aquele espaço público tenha sido construído pelo Estado para outros fins.

Portanto, em termos generalizantes, percebemos que a forma lógica de autoorganização presente nas dinâmicas de habitar os espaços públicos dos moradores do Conjunto Ceará é, sobretudo, algo que se desenrola no tempo de maneira direta, sem intermediários. Sendo os próprios moradores que imprimiram uma produção do espaço em que vivem.

Em correlação a isso, durante nossa pesquisa observamos na produção autoorganizada dos espaços públicos de vizinhança, a característica da horizontalidade. Como afirma Debrun (1996: 18), podemos dizer que "houve sujeitos na auto-organização, mas não o Sujeito da auto-organização”. As resistências apre- 
endidas não vêm de lideranças constituídas e não há como estabelecer uma porcentagem em suas produções, para cada um dos agentes, de acordo com o que fizeram ou não fizeram no processo. Logo, o resultado da resistência não pertence a ninguém privadamente e, como espaços públicos, os locais acabam renovando seus caracteres de pertencimento coletivo.

Outrossim, nas entrevistas com os moradores, sempre em paralelo com as percepções de que as suas ações cotidianas naqueles espaços públicos de vizinhança constituem algo de fato "bom" para vida social do Conjunto Ceará, também são acompanhadas percepções de que aquelas mesmas ações "precisam ser terminadas".

Nas falas dos cidadãos do Conjunto Ceará, a produção auto-organizada do espaço, feita pelos próprios moradores, não é vista como algo fixo. As representações dessa produção surgem com o mesmo sentido das chamadas "gambiarras", vistas como incompletas, deslegitimadas pelo pouco capital simbólico e social que possuem frente ao "monopólio do fazer" do Estado na produção dos espaços públicos.

Porém, ao naturalizarmos essa concepção no senso comum, deixamos de perceber a nossa capacidade de autotransformação social e, principalmente, deixamos de ver imersas no cotidiano que as mais variadas espécies dessas transformações continuam a acontecer em todos os cantos tacitamente.

\section{Considerações finais}

Temos conhecimento que há uma infinidade de formas de habitar um território e que não se restringem as duradouras ou cristalizadas, tais como as produzidas pelo Estado, pela Família e pelas Igrejas. Há formas de habitar um espaço público de vizinhança que se relacionam de modo mais abrangente às múltiplas formas de relações/encontros sociais fragmentados entre seres humanos durante seus cotidianos e, cujas formalizações sustentam, apesar disso, mais que tudo, a sociedade como tal (SIMMEL, 2006).

Portanto, para que os espaços públicos de vizinhança do Conjunto Ceará não pereçam diante do tempo e das violências impostas aos territórios periféricos, lutas são alavancadas ${ }^{10}$, tanto por atores organizados em instituições e movimento sociais, quanto pela política do cidadão comum em seus afazeres cotidianos e que consistem em habitar aquele território. Algo que pode se revelar mais evidentemente, conforme se dê o enfraquecimento ou não da dominação simbólica do Estado.

Com esteio nessa dinâmica, observamos que as resistências aqui descritas são evidências das relações de classe na sociabilidade da vida nas cidades. Já que, enquanto as elites têm a possibilidade de criar espaços segregados, a exemplo dos "Alphavilles", distantes das populações e das mazelas que residem nas periferias das grandes cidades, os mais pobres agregam melhorias feitas com suas próprias mãos aos locais onde habitam (BAUMAN, 2009).

Outra consideração, trata de como relações de vizinhança não apenas conformam articulações políticas e movimentos sociais, mas constroem uma auto-organização do espaço público. Entre os usos e contra-usos (LEITE, 2002) dos lugares, os cidadãos comuns qualificam os espaços urbanos como espaços públicos através de sua política.

${ }^{10}$ Nos baseamos pela ideia de alavanca em Humberto Maturana (apud FLICKINGER e NEUSER, 1994), no qual algum tipo de perturbação atua como propulsora de configurações, mesmo que não as determinem. 
Nesse sentido, o lugar não é tecido apenas por movimentos organizados ou pelos dispositivos de controle do Estado. Os moradores comuns e seus vizinhos também fazem política: a política do cotidiano.

Concordamos, assim, com Hannah Arendt (1999), para quem, a política não se define exclusivamente por meio das atividades do Estado. Nas palavras de Arendt (1999: 11), o "livre agir é agir em público, e público é o espaço original do político". Logo, são de diversas formas políticas de habitar que os espaços públicos de vizinhança são criados e defendidos fisicamente, além de suas regras simbólicas, pelas quais os acontecimentos da vida em sociedade fazem-se inteligíveis para os que deles participam.

São os "laços de convivência" entre os cidadãos comuns, moradores do Conjunto Ceará, que agenciam a produção dos espaços públicos de vizinhança como característico de um pedaço ou de vários pedaços. Pois, como afirma Magnani (2002: 193), os pedaços são produzidos numa "peculiar rede de relações que combina laços de parentesco, vizinhança, procedência, vínculos definidos por participação em atividades comunitárias, desportivas etc.”.

Foi assim que dentre as produção dos espaços públicos tratadas durante o escopo das pesquisas efetivadas, a que mais nos impressionou foi, sem dúvidas, a auto-organizada. A realização da ação política dos cidadãos comuns que juntam suas forças nos laços solidários dos seus pares e para além de "se fazer ouvir" pelo poderes públicos, conseguem dar as respostas eles próprios aos seus dilemas de vida.

A auto-organização, para concluirmos, é um processo pelo qual, a partir de ações desencadeadas por si mesmas, agentes, como os moradores do Conjunto Ceará na cidade de Fortaleza, transformam os espaços públicos que fazem parte de suas vidas, superando dificuldades e atualizando potencialidades.

A produção auto-organizada dos espaços públicos de vizinhança pelos moradores do Conjunto Ceará é parte vital de uma forma de habitar inventiva, astuciosa e cotidiana.

Como Clavel (2015) traz à inteligibilidade, em termos abstratos habitar é tanto inventar, como sempre "a descobrir" e se difere da rigidez funcional característica do que é apenas "habitat". Portanto, se nos primórdios do bairro, a produção do espaço público deu-se exclusivamente pelo Estado, por se tratar de um projeto urbanístico vinculado a uma política pública de habitação, no decorrer do tempo, além de lutas por preservação e por apelo ao poder público, atestamos também, produções auto-organizadas do habitar nos espaços públicos, que não apenas são transformados, mas se transformam e experimentam a transformação como tal.

No âmbito mais comum e cotidiano dos moradores, a cada intervenção deles nas calçadas, ao plantar e aguar as árvores dos canteiros das avenidas, ao recolher o lixo em local público e mais uma lista de coisas, é possível ver auto-organização. Deixemos a última palavra com a fala de Dona Socorro, uma antiga moradora:

\footnotetext{
Quando eu vim pra cá [referindo-se à reunião do Fórum, realizada a céu aberto no Polo de Lazer do bairro], meu marido falou assim: "não vai falar besteira", mas a gente fala besteira pelas besteiras que são feitas. [...] Ó, eu me sinto dona do pedaço da Avenida $B$ onde eu moro. O porquê? Porque eu me levanto quatro e meia da manhã, eu cuido das minhas plantas do canteiro, eu varro, apanho lixo sem luva, com essas mãos que tá aqui inteirinha. [...] A Prefeitura cuida, a comunidade tem que cuidar também. (Moradora Socorro Guedes)
} 
Recebido em 30 de setembro de 2020.

Aceito em 12 de dezembro de 2020.

\section{Referências}

AGIER, Michel. Do direito à cidade ao fazer-cidade: o antropólogo, a margem e o centro. Revista Mana, 21 (3): 483-498, 2015.

ARENDT, Hannah. O que é política? Rio de Janeiro: Bertrand Brasil, 1999.

AUGÉ, Marc. Não lugares: Introdução a uma antropologia da supermodernidade. Campinas: Papirus, 2012.

BAUMAN, Zygmunt. Confiança e medo na cidade. Rio de Janeiro: Jorge Zahar Ed., 2009.

BREVIGLIERI, Marc. Penser l'habiter, estimer l'habitabilité. Revue Tracés - Bulletin technique de la Suisse romande, 23: 9-14, 2006.

CERTEAU, Michel de. A invenção do cotidiano: artes de fazer. Petrópolis: Vozes, 1998.

CLAVEL, Mäité. Elementos para uma nova reflexão sobre o habitar. Revista Antropolítica, 38: 147-167, 2015.

DEBRUN, Michel. “A ideia de auto-organização”. In: DEBRUN, M.; GONZALEZ, M. E. Q.; PESSOA JR., O. (orgs.). Auto-organização: estudos interdisciplinares em filosofia, ciências naturais e humanas, e artes. Campinas: UNICAMP, Centro de Lógica, Epistemologia e História da Ciência, 1996. pp. 3-23.

DURKHEIM, Émile. Lições de sociologia: fúsica dos costumes e do direito. São Paulo: EDIPRO, 2015.

FLICKINGER, Hans-Georg; NEUSER, Wolfgang. A teoria de auto-organização: as raízes da interpretação construtivista do conhecimento. Porto Alegre: EDIPUCRS, 1994.

HONNETH, Axel. Luta por reconhecimento: a gramática moral dos conflitos sociais. São Paulo: Editora 34, 2009.

IBGE. Instituto Brasileiro de Geografia e Estatística. Censo de 201O. Disponível em: $\quad$ www.ibge.gov.br/estatisticas/sociais/trabalho/9662-censo-demografico2010.html. Acesso em: 29 mar. 2011.

LEITE, Rogério Proença. Contra-usos e Espaço Público: notas sobre a construção social dos lugares na Manguetown. Revista Brasileira de Ciências Sociais, 17 (49): 115-134, 2002.

MAGNANI, J. G. C. De perto e de dentro: notas para uma etnografia urbana. $R e-$ vista Brasileira de Ciências Sociais, 17 (49): 11-29, 2002.

PERRY, C. A. The neighborhood unit. Nova York: Plano regional de Nova York, 1929. 
SIMMEL, Georg. Simmel. Organização de Evaristo Moraes Filho. São Paulo: Ática, 1983.

SIMMEL, Georg. Questões fundamentais da sociologia: indivíduo e sociedade. Rio de Janeiro: Jorge Zahar Editora, 2006.

VIANA, Maria Diógenes. A história do Conjunto Ceará: suas lutas e conquistas. Monografia. História. UECE, 1996. 